Int. J. Electrochem. Sci., 12 (2017) $8777-8792$

International Journal of

ELECTROCHEMICAL

SCIENCE

www.electrochemsci.org

\title{
Modified Glassy Carbon Electrode with Galvanized Copper Nanowires by Palladium and Carbon Nanotubes for Speciation of Dihydroxybenzene Isomers
}

\author{
Najmeh Sabbaghi, Meissam Noroozifar ', Masoumeh Tohidinia and Majid Farsadrooh \\ Department of Chemistry, University of Sistan and Baluchestan, Zahedan, P.O. Box 98135-674, Iran \\ *E-mail: $\underline{\text { mnoroozifar@chem.usb.ac.ir }}$
}

doi: $10.20964 / 2017.09 .64$

Received: 26 February 2017 / Accepted: 20 July 2017 / Published: 13 August 2017

\begin{abstract}
A new modified glassy carbon electrode (GCE) with galvanized copper nanowires by palladium (CuNWs-Pd) and carbon nonotubes (CNTs) has been used for the simultaneous determination of hydroquinone (HQ), catechol (CC) and resorcinol (RS) as water pollutions. The modifier,Pd/CuNWsCNTs, was characterized by field emission scanning electron microscopy and electrochemistry. Different electrochemical techniques such as cyclic voltammetry, differential pulse voltammetry (DPV) and chronoamperometry were used for the electrochemical study of the proposed modified electrode toward HQ, CC and RS electrooxidation. Based on the experimental results, the calibration are linear with two segmented 1-99 and 99-228 $\mu \mathrm{M}$ for HQ, 1-280 $\mu \mathrm{M}$ for CC and with two segments 1-33 and 33-228 $\mu \mathrm{M}$ for RS. The detection limits were obtained $0.4,0.6$ and $0.8 \mu \mathrm{M}$ and the diffusion coefficient calculated $6.5 \times 10^{-5}, 1.6 \times 10^{-5}$ and $8.5 \times 10^{-6} \mathrm{~cm}^{2} \mathrm{~s}^{-1}$, for the HQ, CC and RS, respectively. Moreover, GCE/Pd/CuNWs-CNTs was successfully used for simultaneous determination of HQ, CC and RS in real samples by DPV technique.
\end{abstract}

Keywords: Galvanized copper nanowires by palladium, Electrochemical sensor, Speciation, Dihydroxybenzene isomers.

\section{$\underline{\text { FULL TEXT }}$}

(C) 2017 The Authors. Published by ESG (www.electrochemsci.org). This article is an open access article distributed under the terms and conditions of the Creative Commons Attribution license (http://creativecommons.org/licenses/by/4.0/). 